\title{
current events
}

This section carries events of interest to the synchrotron radiation community. Full or partial inclusion is subject to the approval of the Main Editors, to whom all correspondence should be sent.

\section{Australia gets its long awaited synchrotron - Victoria takes the initiative}

Victoria's Premier, Steve Bracks, announced that a national synchrotron facility would be established at Monash University - the first of its kind in Australia. The announcement came as a surprise to some of the other states as the Federal Government had been considering four separate applications to support the construction of a synchrotron under the Major National Research Facilities (MNRF) program. The applications for the MNRF were to be finalized in August 2001, but the Victorian government made the decision to go it alone and begin the project. The most vocal protestor has been the Queensland Premier, Peter Beatie, but the Federal Government has given backing to the Victorian decision to establish Australia's first national synchrotron facility.

The Victorian Government would join with Monash University and other project partners to enable the construction of the $\$ 157$ million facility, starting in 2001/02. The State Government will provide up to $\$ 100$ million for the synchrotron, with the balance from other project partners, such as research institutions and the private sector. Australia is the largest OECD country without a synchrotron and its scientists have, for more than two decades, been trying to persuade their paymasters to fund their own synchrotron. The Australian community has built their national beamlines at the Photon Factory in Japan and at the APS in Chicago. The new site is near the highly acclaimed Monash Medical Precinct, next to five key CSIRO divisions, and is within Australia's largest high-tech industry cluster. Complementary to the synchrotron, Monash recently announced plans to construct a $\$ 300$ million International Centre for Science, Technology and Emerging Industries. The plans include a science-based secondary college and a 180-bed hotel and conference centre.

The design parameters are not yet fully defined but it is expected that the storage ring will have a machine energy of $3 \mathrm{GeV}$. It is going to be about $57 \mathrm{~m}$ in diameter with a beam emittance of around $12 \mathrm{~nm}$ rad.

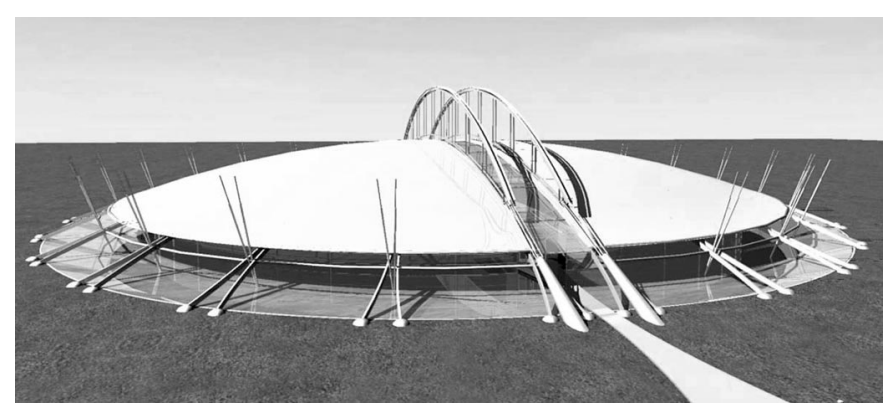

An impression of the new Australian synchrotron.

\section{Gopal Shenoy returns to research}

Gopal Shenoy is to step down as Senior Scientific Director of APS and return to research, effective as of 1 October 2001. Gopal and Yang Cho are regarded as the founding fathers of the APS, having developed the proposal to build it at Argonne some 18 years ago.

\section{David Norman to retire from Daresbury}

Professor David Norman, who was the director of the Synchrotron Radiation Department at Daresbury during the DIAMOND controversy, is to take an early retirement from September 2001.

\section{Hiromichi Kamitsubo moves on}

Professor Hiromichi Kamitsubo, who led the SPring-8 project from the ground-breaking, resigned as the Vice President of JASRI and Director General of Synchrotron Radiation Laboratory. He became the Vice Chairman of JASRI after the late Professor Minoru Oda. He is expected to continue to develop the international collaboration. Professor Akira Kira has undertaken the post of Director General of JASRI from 1 August 2001.
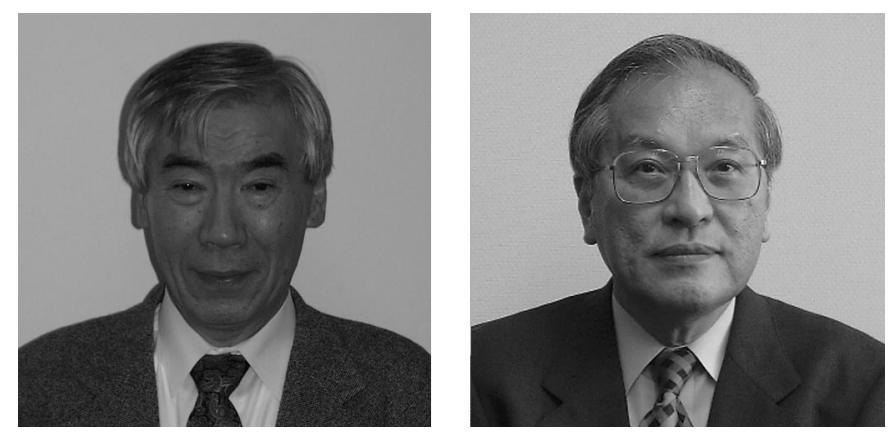

Professor Hiromichi Kamitsubo and Professor Akira Kira.

\section{Jochen Schneider awarded European Crystallography Prize}

The European Crystallographic Association is to award the second European Crystallography Prize to Professor Jochen R. Schneider of the HASYLAB at DESY, Hamburg, Germany. Professor Schneider is being recognized for his pioneering work on the application of gamma-ray spectroscopy and his high-energy synchrotron radiation studies, as well as his more recent involvement in the development of the free-electron laser.

The European Crystallography Prize, which includes a monetary award as well as a certificate of recognition, will be presented during the Opening Ceremony of the upcoming 20th European Crystallographic Meeting to be held in Krakow, Poland, on 25-31 August 2001, at which Professor Schneider will describe the work for which he is being honoured.

\section{SESAME appoints technical director}

Dr Einfeld, who had been responsible for the construction of the synchrotron radiation source ANKA at Karlsruhe, has accepted an offer to become Technical Director of SESAME. He would hold a Professorial position at the Al Balqa Technical University and has been appointed by UNESCO on behalf of SESAME. The government of Pakistan has formally asked for its membership of SESAME, while the UK has formally become on Observer to SESAME. The ground-breaking ceremony for the SESAME building took place on 27 August 2001. 